
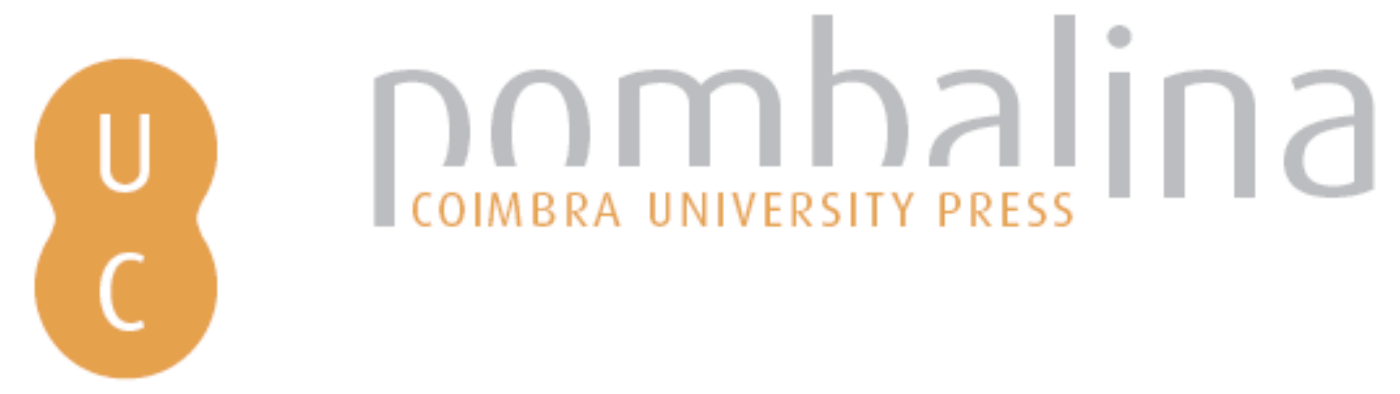

\title{
A geografia da criminalidade
}

Autor(es): $\quad$ Ferreira, Jorge; Martins, José

Publicado por: Imprensa da Universidade de Coimbra

URL

persistente:

URI:http://hdl.handle.net/10316.2/31157

DOI:

DOI:http://dx.doi.org/10.14195/978-989-26-0244-8_69

Accessed : $\quad$ 26-Apr-2023 16:11:27

A navegação consulta e descarregamento dos títulos inseridos nas Bibliotecas Digitais UC Digitalis, UC Pombalina e UC Impactum, pressupõem a aceitação plena e sem reservas dos Termos e Condições de Uso destas Bibliotecas Digitais, disponíveis em https://digitalis.uc.pt/pt-pt/termos.

Conforme exposto nos referidos Termos e Condições de Uso, o descarregamento de títulos de acesso restrito requer uma licença válida de autorização devendo o utilizador aceder ao(s) documento(s) a partir de um endereço de IP da instituição detentora da supramencionada licença.

Ao utilizador é apenas permitido o descarregamento para uso pessoal, pelo que o emprego do(s) título(s) descarregado(s) para outro fim, designadamente comercial, carece de autorização do respetivo autor ou editor da obra.

Na medida em que todas as obras da UC Digitalis se encontram protegidas pelo Código do Direito de Autor e Direitos Conexos e demais legislação aplicável, toda a cópia, parcial ou total, deste documento, nos casos em que é legalmente admitida, deverá conter ou fazer-se acompanhar por este aviso. 


\section{TRUNFOS DE UMA}

\section{EOGRAFIA ACIVA}

\section{DESENVOLVIMENTO LOCAL,}

AMBIENTE,

ORDENAMENTO

E TECNOLOGIA

Norberto Santos

Lúcio Cunha

COORDENAÇÃO 
Jorge Ferreira, José Martins

eGeo - Centro de Estudos de Geografia e Planeamento Regional-FCSH - UNL

\section{A GEOGRAFIA DA CRIMINALIDADE}

\section{INTRODUÇÃO}

Os territórios estão constantemente a sofrer alterações, quer de cariz interno quer externo, modificando e alterando o estilo e qualidade de vida da população. Presentemente, assiste-se a uma maior preocupação e necessidade em estudar e analisar os fenómenos crescentes do território, bem como proceder a um planeamento que vise melhorar a mobilidade urbana e controlar a segurança interna das áreas urbanas, devido aos diversos problemas e necessidades que estes núcleos acarretam. A diversidade espacial do nosso território é conhecida e estudada desde há muito tempo, contudo, raramente se pensa e articula este conhecimento com os fenómenos criminais. A criminalidade, tal como outros fenómenos, desenvolve-se sobre o território, tendo por isso uma matriz geográfica. Segundo as teorias da criminologia, tratar apenas dados reportados é insuficiente para efectuar uma análise correcta da criminalidade e criar políticas de segurança e prevenção do fenómeno criminal.

Com o desenvolvimento de aplicaçôes de Sistemas de Informação Geográfica (SIG) desde 1990, os analistas criminais têm usado e ponderado os princípios da Geografia de forma a perceber e criar mecanismos de prevenção e segurança da população. Vários especialistas afirmam que o mapeamento da criminalidade tem um impacto no entendimento do crime e dos problemas sociais. Desta forma, a geografia aplicada tem um papel preponderante neste tipo de fenómeno. Se conhecermos uma determinada área e a forma como essa afecta as áreas de proximidade, podemos perceber como e onde se localiza determinado fenómeno ou acontecimento. Isto é, a Geografia da Criminalidade é uma importante ferramenta de apoio à decisão em questôes de segurança pública e prevenção do crime.

Este documento expóe um exemplo experimental simulado do estudo criminal (sem dados reais georreferenciados), e tem como objectivos principais: (i) conhecer a distribuição do fenómeno criminal; (ii) perceber a dimensão e espacialização das forças de segurança; (iii) reconhecer áreas problemáticas e vulneráveis da cidade de Lisboa; e (iv) propor ferramentas para a segurança e prevenção da criminalidade.

\section{CRIMINALIDADE E GEOGRAFIA}

É difícil encontrar um cidadão que não se preocupe com o aumento do fenómeno da criminalidade na sociedade actual. $\mathrm{O}$ crime, inerente à própria condiçáo social tem sofrido 
ao longo da história inúmeras mutaçóes. Não se trata apenas do aumento da criminalidade ordinária (furtos e roubos), ou do próprio sentimento de insegurança da população em geral, mas também, e principalmente, da perda de confiança dos cidadáos perante o Estado, que é e deve ser, o principal garante da "paz social".

A segurança da população está constantemente a ser ameaçada pelo sentimento de insegurança global perante as condiçóes e situaçóes de risco numa sociedade. Ao longo dos tempos, o sentimento de insegurança e de risco vai sendo modificado e alterado pelas condiçóes sociais e pela própria noção de insegurança e criminalidade de cada sociedade. Para alguns criminologistas esta é "A Sociedade do Risco» (Agra, in Cusson 2007:7). No entanto, não será esta também a Sociedade da Informação e do Conhecimento? Assumindo que sim, deverão ser criadas políticas de informaçáo conducentes à geraçáo de conhecimento, necessário para a análise do fenómeno criminal, de modo a reduzir o risco e a insegurança nas sociedades. Este é em si, o fundamento da Criminologia.

A Criminologia pretende conhecer a realidade e o próprio fenómeno criminal. Procura perceber e identificar a lógica interna do fenómeno criminal sem grande dispersão nas suas causas, onde o fenómeno criminal é um conjunto de processos e situaçóes, onde o crime é o centro (Cusson 2007). Pode assim afirmar-se que o fenómeno criminal é um processo construtivo de elementos ligados entre si, com relaçóes de forte dependência, que se adaptam ao meio, à situação e ao contexto.

$\mathrm{O}$ estudo da segurança dos espaços urbanos designa-se por criminologia ambiental. A criminologia ambiental estuda não só o próprio fenómeno criminal mas todo o ambiente físico, social, económico e histórico em que esse fenómeno ocorre. Esta área da criminologia pretende reduzir o número de ocorrências com o conhecimento do fenómeno e do espaço. Os alicerces do mapeamento criminal derivaram da criminologia ambiental que é o estudo do crime da vitimização e de como estão relacionados com o espaço geográfico. A violência já não é a mesma e é mutante no tempo e no espaço, sendo crucial a relação entre crime e o lugar. Desta forma, a Geografia é uma das ciências com maior interesse para a análise do fenómeno criminal (Wilson e Smith, 2008). Nesta ciência não se procura explicar o motivo pelo qual criminoso comete um crime, mas sim identificar padróes de comportamento e de que forma podem os factores ambientais, económicos e sociais criar a oportunidade para o crime. A base da criminologia ambiental refere que existe uma ligação entre o comportamento criminal e o ambiente físico e social. $\mathrm{O}$ crime deve ser visto não como um acto isolado e casual, mas sim num contexto específico, que possa fomentar maiores ou menores oportunidades para a ocorrência de um determinado fenómeno ${ }^{1}$.

Com o desenvolvimento de aplicaçôes de Sistemas de Informação Geográfica (SIG), os analistas criminais têm usado e ponderado os princípios da Geografia, de forma a perceber e criar mecanismos de prevenção e segurança da população. O papel da geografia aplicada na segurança pública tem vindo a ser referenciada há mais de uma década, por autores como Hall e Willbanks (1997). Estes autores afirmam que o mapeamento da criminalidade tem um impacto no entendimento do crime e dos problemas sociais. Referem que os SIG e a cartografia digital dão maior reconhecimento ao espaço, como matriz de análise. Os autores referem ainda a necessidade da Geografia para o estudo da segurança e do crime, afirmando que esta ciência é focada no mundo real, nas relaçóes e dependências, dando um carácter e um conhecimento sobre o lugar de ocorrência do fenómeno. Esta

\footnotetext{
${ }^{1}$ In Portal da Segurança com Cidadania (ver endereço web).
} 
abordagem poderá resumir «...um renascimento do pensamento geográfico» (Wilson e Smith 2008).

A combinação da geografia com as teorias criminais e o mapeamento da criminalidade, são uma importante ferramenta de apoio à decisão das questôes relacionadas com a segurança pública e prevenção da criminalidade. Os SIG e a análise espacial permitem visualizar e analisar informaçáo de ameaças que podem resultar em novas políticas de combate ao fenómeno, em múltiplas escalas de análise, processando e representando informação, com um contexto e utilidade, de forma a gerar conhecimento através do conceito de área e espaço envolvente.

Numa publicação de 1977 intitulada «Crime Analysis in Support of Patrol», do instituto de justiça norte-americano, os seus autores discutiam as sofisticadas abordagens técnicas baseadas na matemática, numa tentativa de providenciar uma distribuiçáo mais realística do patrulhamento de efectivos e ordenação de recursos. No entanto concluíram que nenhuma força policial tinha aplicado essa técnica experimentalista, muito devido às deficiências e lacunas dos softwares informáticos da época. Actualmente já existem registos de alocaçáo de recursos focados no arquivo e no balanço entre os incidentes e uma determinada área geográfica (Bruce 2009). Desta forma, o primeiro passo a ser dado na prevenção criminal passa por analisar o estado dos incidentes ao longo dos anos e detectar áreas homogéneas dos incidentes (padróes). Sendo este o ponto de partida da análise criminal. Diversos autores afirmam que uma grande concentração de incidentes pode ser definida como uma "área quente", sendo esta, uma localização propícia ao crime (Akpinar \& Usul 2003). Os SIG permitem representar e analisar espacialmente incidentes e detectar padróes do fenómeno criminal em diferentes dimensóes de análise.

\section{O MODELO DE ANÁlISE CRIMINAL}

O modelo de análise desenvolvido em Sistemas de Informação Geográfica é experimental, servindo para o apoio à análise sócio-criminal. É experimental, no sentido em que não foram utilizados dados reais de criminalidade reportada e serve como exemplo prático da utilização de ferramentas SIG, demonstrando a importância da Geografia e a sua eficácia na análise do fenómeno criminal. Neste modelo, utilizaram-se em grande parte, técnicas de análise exploratória, estatística descritiva e estatística espacial. Os factores sociológicos não tiveram a devida ponderação, sendo importante referir, que não se deve descurar a abordagem sociológica deste fenómeno dada a sua importância e clara influência. A componente abordada neste exemplo prático pretende: (i) analisar o contexto/envolvência espacial do incidente; (ii) os recursos envolvidos; e (iii) de que forma pode a componente espacial afectar ou não uma determinada localização de ocorrência de um crime. $\mathrm{O}$ objectivo final deste modelo tem como pretensão compreender a dimensão e espacialização das forças de segurança e reconhecer áreas problemáticas e vulneráveis da cidade de Lisboa a uma micro-escala. Adaptado a casos reais, o modelo desenvolvido permitirá o desenvolvimento de ferramentas para a optimização dos percursos e a identificação de padrôes de distribuição do crime.

A rede urbana, as acessibilidades, os custos de deslocação são cada vez mais importantes na definição de políticas de intervenção. Conhece-se também há já muito tempo, a diversidade espacial do nosso território, contudo, raramente se pensa nessa mesma diversidade e, acima de tudo, na conjugação das acessibilidades e da criminalidade. A típica análise de 
acessibilidades, que não considera o território no seu todo, baseada apenas numa lógica de arco/nó das infra-estruturas, é incompleta, pois deve ser avaliada para todo o território e náo apenas sobre a rede de infra-estruturas (Julião 2001). Desta forma, construiu-se um modelo de superfície de acessibilidades, com a delimitaçáo à cidade de Lisboa. Foram utilizados os temas geográficos da altimetria, a rede viária e a localização das esquadras da Polícia de Segurança Pública de Lisboa.

O primeiro passo consistiu na reclassificação da rede viária de Lisboa, o que permitiu ter valores específicos de acordo com o tipo de eixo e velocidade média do mesmo. Esta reclassificação teve em conta, o custo de atravessamento de cada célula segundo o tipo de via a atravessar. Seguidamente foi criado um modelo digital de terreno (MDT) ${ }^{2}$ para Lisboa. Posteriormente, procedeu-se ao cálculo de Declives de Vertentes em graus e ao cálculo das tangentes. Por fim, multiplicou-se o resultado da tangente à rede de acessibilidade, de forma a conseguir obter um gradiente de esforço com recurso ao declive do terreno. Todos estes dados serviram para gerar uma "grelha" de custos com altimetria e uma "grelha" de custos sem altimetria, que definem a independência do custo de movimento por cada célula. $\mathrm{O}$ valor de cada célula representa o custo por unidade de distância pelo movimento através de cada célula e que poderá ser representada em diferentes custos.

As operações de análise espacial de uma superfície de custos originaram dois resultados distintos, a saber: Custo de Distância e Distribuição de Custos. O Custo de Distância identifica para cada célula o menor custo de distância acumulado de uma superfície de custos com base em uma ou mais fontes localizadas, designada neste exercício por Taxa de Esforço. A distribuiçáo de custos identifica áreas que conseguem ser alcançadas com o menor custo acumulado. $\mathrm{O}$ custo de atravessamento com a condicionante altimétrica é significativamente elevado em algumas áreas da cidade devido às condiçóes físicas do terreno. No entanto, o raio de menor custo de atravessamento é maior. $\mathrm{Na}$ deslocação sem altimetria, há um menor custo de distância devido ao facto da análise considerar apenas a rede viária como factor condicionante de atravessamento de cada célula. Contudo, o raio de custo assenta somente na rede viária, ignorando a área envolvente. Realizou-se assim uma sobreposiçáo ponderada das duas grelhas de custos, de forma a gerar uma única grelha, representativa do valor médio de custo de distância. Nesta análise, teria sido importante a utilização de dados de criminalidade reportada, contudo esta informaçáo é confidencial, sendo que para efeitos de demonstraçáo optou-se por criar dados criminais segundo um critério específico ${ }^{3}$.

Seguidamente, desenvolveu-se um modelo de análise de superfícies com os temas espaciais das ocorrências criminais simuladas, da taxa de esforço concebida no modelo anterior, da populaçáo residente por subsecçáo estatística em 2001 e do Plano Director Municipal (PDM). É de referir que, para efeitos de análise exploratória, os dados criminais foram tidos como reais, elaborando-se assim sobre eles, um conjunto de conclusóes. Numa análise mais pormenorizada poder-se-ia ter aplicado ao modelo a variável tempo, no entanto face à utilização de dados fictícios, tal não se justificou, para já. Inicialmente realizou-se também

\footnotetext{
${ }^{2}$ MDT: Estrutura numérica de dados que representam a distribuição espacial de uma variável quantitativa e contínua do relevo da superfície terrestre, usando curvas de nível.

${ }^{3}$ De forma a tornar o projecto mais realista, colocara-se mil quatrocentos e dezanove pontos fictícios (incidentes) em locais com maior número de equipamentos comerciais e de entretenimento e estaçóes de transportes públicos e duzentos pontos nos locais com maior número de população residente. Assumiu-se que estes pontos seriam referentes a furtos e roubos.
} 
uma operação de análise de estatística espacial empregando a densidade de Kernel com os dados de ocorrências criminais para a cidade de Lisboa (dados náo reais). A técnica de Kernel é um método estatístico de estimação de densidade por suavização ou interpolação, permitindo seleccionar a instabilidade de um incidente numa determinada área (Eck et al. 2005). Esta operação permite identificar as áreas quentes de criminalidade. Seguidamente realizouse o mesmo tipo de técnica de estatística espacial, mas utilizando uma implantação linear segundo a rede viária. Pode-se assim verificar que a criminalidade apresenta vários padróes espaciais, de onde se destaca, com maior densidade, a "baixa lisboeta" e várias áreas com menor densidade dispersas pela cidade. Posteriormente foram reclassificadas as densidades de crimes de menor para maior densidade, de forma a sobrepor este gradiente com a taxa de esforço para os veículos policiais. Seguidamente, criou-se a taxa de incidência criminal por freguesia. Esta taxa foi calculada segundo uma análise de regressão ponderada utilizando o contexto espacial de Kernel. Esta operação suaviza os valores absolutos e aproxima-os da curva da distribuição normal, permitindo reduzir as disparidades da distribuição (Harries 1999). A taxa de incidência sofreu depois uma reclassificação ponderada de menor para maior desvio-padrão, de forma a harmonizar os resultados obtidos. De referir ainda que este tipo de taxa de incidência, se utilizada isoladamente, pode gerar resultados de análise incorrectos, devido ao facto de puderem existir valores elevados de ocorrências em áreas com pouca população residente. $\mathrm{O}$ tipo de uso solo da cidade foi a última informação de base a ser analisada, de forma a cruzar esta informação com as densidades criminais, a taxa de incidência criminal e a taxa de esforço, calculadas anteriormente. Desta forma o PDM foi reclassificado de maior para menor ponderaçáo, de forma a ponderar essencialmente sobre as redes de acessibilidade, as áreas urbanas comerciais, residenciais consolidadas e propostas. As restantes classes foram reclassificadas com uma menor ponderaçáo (esta opção teve em conta uma hipotética análise de furtos e roubos a património e pessoas). Com esta operação pode pressupor-se que as áreas com maior risco são as áreas históricas e de maior acessibilidade da cidade. Para concluir a análise, foi realizada uma sobreposição ponderada com as densidades criminais, a taxa de esforço de deslocação, a taxa de incidência criminal e o tipo de solo, de forma a criar um índice de risco de potenciais locais para a ocorrência de incidentes. Com esta sobreposição foi atribuído um maior peso percentual às densidades criminal e à taxa de esforço (75\%), seguindo-se o tipo de solo (15\%), e com menor peso, a taxa de incidência criminal (10\%).

Este tipo de cartografia de risco permite às unidades policiais: (i) gerir eficazmente os seus efectivos; (ii) redesenhar as suas áreas de responsabilidade; e (iii) perceber as suas carências internas. Desta forma é possível tornar mais eficiente o combate ao fenómeno criminal. Pode-se assim concluir que o potencial risco de ocorrência de incidentes criminais (com dados simulados) se situa nas áreas periféricas, no centro da cidade, em núcleos habitacionais mais problemáticos e nas áreas de maior afluência turística e de "activos" da cidade. É visível também a falta de esquadras em áreas mais vulneráveis da cidade. Este índice, não mostra necessariamente as áreas onde o registo de incidentes é mais expressivo, mas sim as áreas que, para além do número significativo de incidentes, apresentam um défice na mobilidade de efectivos policiais, uma taxa de incidência significativa e áreas (mais) vulneráveis no que concerne à sua tipologia sócio-económica. Com esta análise poder-se-á pensar numa reorganização territorial do dispositivo policial, de forma a suprimir estas carências. 
Figura 1 - Índice de Potencial Risco de Ocorrência de Incidentes Criminais

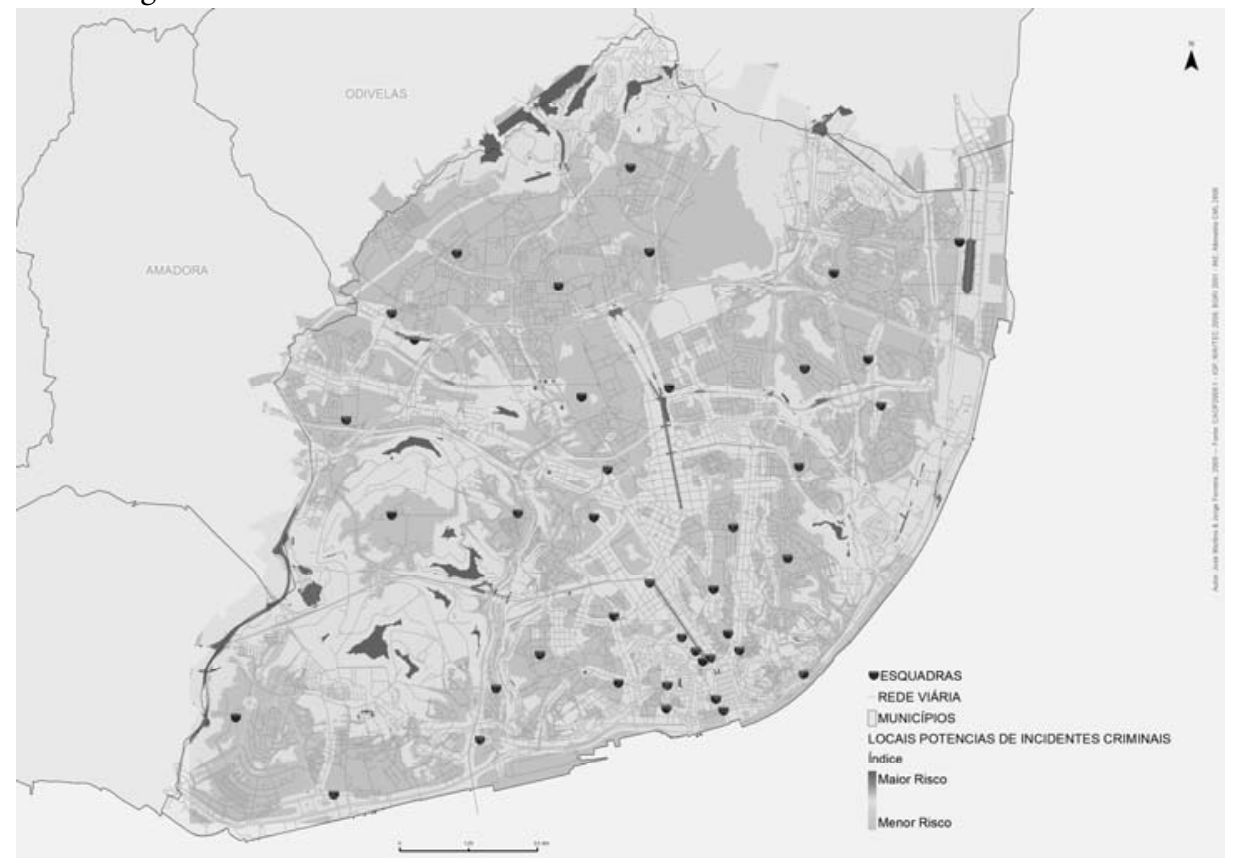

Fonte: Elaboração Própria, 2009

\section{3- CONSIDERAÇÓES FINAIS}

A Geografia e as tecnologias de análise espacial a ela associadas evoluíram muito nos últimos anos. Esta realidade permitiu - às instituiçóes com responsabilidades ao nível da segurança - desenvolver maiores capacidades em termos de análise criminal e responder de forma mais eficaz às mudanças da sociedade. $\mathrm{O}$ crime deve ser analisado num contexto de ameaças e transformaçôes das próprias sociedades. Será também determinante a avaliação das condiçóes demográficas, económicas, sociais e ecológicas que podem afectar o próprio acto criminal. Só percebendo as verdadeiras ameaças e desenvolvendo soluçóes com recurso à geografia aplicada e aos sistemas de informação geográfica é que se poderá analisar o actual mapa da criminalidade, bem como os problemas que influenciam o próprio acto criminal. A análise espacial avançada veio permitir identificar padróes de criminalidade e áreas vulneráveis de crescimento de insegurança. Este tipo de análise facilita o conhecimento com vista à tomada de decisóes estratégicas no combate ao fenómeno criminal. Complementando a análise espacial da criminalidade com o conhecimento empírico das componentes históricas e culturais de um determinado território, pode identificar-se o porquê da ocorrência de um determinado tipo de crime num determinado espaço geográfico e, assim, planear meios e recursos com vista à prevenção e redução da criminalidade. Este trabalho tentou demonstrar (recorrendo a dados criminais simulados), a possibilidade de criar cenários de prevenção e de combate ao fenómeno criminal em Portugal. 


\section{REFERÊNCIAS BIBLIOGRÁFICAS}

Akpinar, E. \& Usul, N. 2004, 'Geographic Information Systems Technologies in Crime Analysis and Crime Mapping', Twenty-Fourth Annual ESRI User Conference, San Diego, CA., ESRI , $2^{\text {nd }}$ edn, p.12.

Avoort, V. 2005, 'The implementation of Geographic Information Systems in law enforcement agencies: a geographic analysis of crime in Estes Park', Universität zu Köln, Geographisches Institut, Köln.

Batella, W., Diniz, A., Teixeira, A. 2008, 'Explorando os Determinantes da geografia do crime nas cidades médias mineiras', Revista de Biologia e Ciências da Terra, vol. 8, no 1, $1^{\circ}$ semestre, pp.21-31.

Bruce, C. 2009, 'Districting and Resource Allocation: A Question of Balance', Geography \& Public Safety, vol. 1, Issue 4, January 2008, Washington, DC, COPS, NIJ, pp.1-3.

Cusson, M. 2007, Criminologia. Casa das Letras, $2^{\text {nd }}$ edn.

Diniz, A. \& Batella, W. 2006, 'Abordagens Espaciais no Estudo da Criminalidade Violenta', II Simpósio Internacional sobre Cidades Médias - Dinâmica Económica e Produção do Espaço, Uberlândia, p.17.

Eck, J., Chainey, S., Cameron, J., Leitner, M. \& Wilson, R. 2005, Mapping Crime: Understanding Hot Spots, Washington, DC, NIJ.

Fernandes, E. 1997, Segurança e Sustentabilidade: Processos Urbanos e Criminalidade na cidade do Porto do Século $X X$, Fac. Arquitectura e Engenharia da Universidade do Porto.

Filbert, K. 2008, 'Targeting Crime in Hot Spots and Hot Places', Geography \& Public Safety, vol 1, Issue 1, February 2008, Washington, DC, COPS, NIJ, pp.4-7.

Harries, K. 1999, Mapping Crime: Principle and Practice, Washington, DC, NIJ.

Johnson, C. P. 2000, 'Crime Mapping and Analysis Using GIS'. Geomatics 2000: Conference on Geomatics in Electronic Governance, Pune, Geomatics Group, Center for Development of Advanced Computing, Pune University Campus, p.5.

Juliáo, R. P. 2001, Tecnologias de Informação Geográfica e Ciência Regional: Contributos Metodológicos para a Definição de Modelos de Apoio à Decisão em Desenvolvimento Regional, FCSH, Univ. Nova de Lisboa.

Loch, C. \& Máximo, A. 2004, 'A Importância do Mapeamento da Criminalidade Utilizando-se Tecnologia de Sistema de Informação Geográfica para Auxiliar a Segurança Pública no Combate à Violência', Departamento de Engenharia Civil, Univ. Federal de Santa Catarina, Brasil, p.6.

Longley, P.; Goodchild, M. F.; Maguire, D.; Rhind, D. 2005, Geographic Information Systems and Science, Wiley Blackwell, $2^{\text {nd }}$ edn.

Mielke, P. D. 2008a, 'Using ModelBuilder for Geographic Information System Tasks', Geography \& Public Safety, vol. 1, Issue 1, February 2008, Washington, DC, COPS, NIJ, pp.8-10.

Mielke, P. D. 2008b, 'Creating Base Maps and Layer Files for Cartographic Consistency', Geography \& Public Safety, vol. 1, Issue 2, July 2008, Washington, DC, COPS, NIJ, pp.9-11.

Mielke, P. D. 2009, 'Determining Anchor Points for Sex Offenders Using GPS Data', Geography \& Public Safety, vol. 2, Issue 1, May 2009, Washington, DC, COPS, NIJ, pp.9-10.

Nery, M. B. 2006, Gestão Urbana: Sistemas de Informação Geográfica e o Estudo da Criminalidade mo Município de São Paulo, Instituto Nacional de Pesquisas Espaciais São José dos Campos, Brasil.

Wilson, R. \& Paulsen, D. 2008, 'Foreclosures and Crime: A Geographical Perspective', Geography \& Public Safety, vol. 1, Issue 3, October 2008, Washington, DC, COPS, NIJ, pp.1-2.

Wilson, R. \& Smith, K. 2008, 'What is Applied Geography for the Study of Crime and Public Safety?', Geography \& Public Safety, vol. 1, Issue 1, February 2008, Washington, DC, COPS, NIJ, pp.1-3.

\section{WeBsites CONSULTADOS}

East Valley Compass, 2009, http://www.eastvalleycompass.org/ (acedido a 15 de Novembro de 2009)

National Institute of Justice, 2009, http://www.ojp.usdoj.gov/nij/maps/ (acedido a 25 de Outubro de 2009)

Portal da Segurança com Cidadania, 2009, http://www.segurancacidada.org.br/index.ph p?option =com_conte nt\&task= view\&id=704 (acedido a 24 de Outubro de 2009)

UCL Centre for Advanced Spatial Analysis, 2009, http://www.casa.ucl.ac.uk/ (acedido a 05 de Novembro de 2009) 